treated almost exclusively of Pau and its climate. On the present occasion he has discussed the merits by comparison of other places which have obtained repute for bringing health to the sick and re-invigorating the valetudinarian. Twenty-five years ago $P a u$ could scarcely boast of more than a quiet reputa tion amongst a small body of English visitors, who, without having arrived there in search of health, had yet derived advantage from the salubrity of its elimate, and had recommended it to others as a place of temporary sojourn. During the season of 1860-61 there were at Pau at least a thousand British sub. jects! In each family there was generally one member with more or less of chest affection, or suffering from some other morbid state; and yet we are assured by Dr. Taylor that from the lst of October to the lst of June following there were only two deaths from phthisis and five deaths from all causes. We must admit with the author that such a remarkably small amount of mortality speaks inferentially much in favour of the salubrity of $\mathrm{Pau}$.

Electro-Physio'ogy and Electro-Therapeutics, showing the best Methods fur the Medical Uses of Electricity. By ALFRED C. Garratt, M.D., Fellow of the Massachusetts Medical Society. pp. 716. 'Boston: Ticknor and Field.

The first edition of Dr. Garratt's treatise has had a quick and extensive circulation amongst the profession in America. Considering that it was a voluminous and expensive work, this speaks much in its favour. The present issue has been slightly increased in size, but diminished in price, the latter of which alterations will not tend to lessen the work in public opinion. The new matter chiefly relates to directions for carrying out "electric sittings" for operating about the face and head with elestric currents, and to a description of the author's "medical battery." The new edition may be said to excel the former one for plain practical purposes, and as a book for reference by the busy practitioner desirons of employing any electrical apparatus for remedial purposes. In it also will be found the minutixe of the mode of proceeding peculiar to the author. Some of the woodeuts might have been less coarse in execution, and tinted paper dispensed with for printing them upon. Dr. Garratt's work may be recommended as giving both full and useful information upon the subject of which it treats.

Dairy Stock: its Selection, Diseases, and Produce; with a Description of the Brittany Breed. By foHN Gamaet, Professor in the New Veterinary College, Edinburgh. With two Plates in Lithograph, and numerous Woodcuts. pp. 3i6. Edinburgh: Jack.

To those who desire to know "all about the cow," we may strongly recommend Mr. Gamgee's little book. We were particularly interested with the chapter "On the Advantages of Spaying Dairy Cows," as that a!so upon "Brittany, its Cows and its People." The following piece of information was less acceptably received by us as we recalled to mind sundry repasts we had made upon fricandeau and spinach. Speaking of the loss of cattle, Mr. Gamgee observes:-

"By pregnant cow's likerwise the loss is great. 300,000 out of the 800,000 are slaughtered in this condition in France; and Charlier estimates the loss of $\$ 48,000$ simply by the calf and its envelopes. It is disgusting to reflect that from the imper. fect inspection of our slanghterhouses calves that are found in cows are sold for human consumption. It is termed 'slink veal." "-p. 262.

Mr. Gamgee's book is nicely illustrated, and would make a useful present to a country cousin.

The Technologist. A Monthly Record of Science applied to Art and Manufacture. Edited by R. L. Sımmonos, F.S.S. London: Kent and Co.

THIS useful periodical has just completed its first volume, and may now be said to have fairly established its claims to the patronage of that portion of the public especially interested in the subjects which it discusses. On glancing over the contents of the volume, we find nearly ninety articles, a good vany of which treat of the various products of the animal, vegetable, and mineral kingdoms, and contain mueh information that is of importance to the medical man. Amongst the papers of general interest are-A Good and Cheap Substitute for Coffee; the Scientific Culture of the Strawberry ; Tea-Substitutes of the Mauritius; the Native Farinas of Jamaica Dugong Oil; Vegetable Waxes; the Potato and its Commercial Products; and the Tortoise-shell of Commerce.

The Editor, who is already so well known by his writings on kindred subjects, has ably performed his task, and many of the articles are from his pen. To both the general and professional reader this magazine will afford a mine of interesting and valuable information.

\section{TREATMENT OF THE AUTUMNAL FORMS OF DIARRHCEA AND DYSENTERY BY NITRIC ACID AND OPIUM.}

\section{To the Editor of THE LANCET.}

SIR, - It was at a seasonable hour that Dr. P. J. Hynes, of Nottingham, placed before the profession, through your journal, the results of his observations on the above subject, as the remedial agents he so highly extols will doubtless by this time have received due attention at the hands of many practitioners. For my own part, I viewed the subject with an eager eye, and sedulously set to work to satisfy my curiosity respecting the merits or demerits of the remedies in question; and I now offer the result of my limited observations to corroborate to a certain extent Dr. Hynes' statements, in hopes that they will be found to coincide with those who may have attempted the same on a more extended scale.

I conducted my experiments in such a manner as to test not only the real virtues that nitric acid and opinm possess in the treatment of diarrhcea and dysentery, but also their relative value when compared with otber remedies. Fuur suitable cases were selected to commence with. One was restricted to a farinaceous diet, with brandy; another had. in addition, chalk mixture and aromatic confection; to a third acetate of lead and opium were administered; and nitric acid and opium, according to Dr. Hynes' formula, to the fourth. All terminated successfully; those who received the stronger remedies recovered soonest, but the nitric acid was in its effects minus the acetate of lead.

I next selected three cases, and administered sulphuric, nitric, and muriatic acids respectively, in combination with opium. The effect was manifest: the nitric acid proved more efficacious than either of the others. I have, moreover, given it a trial in several other instances, and with marked success, but it does not appear to possess the active properties of sugar of lead and tannin.

From the above, I have arrived at the conclusion that the employment of nitric acid in diarrhoea is a remedy of great value, and a useful adjunct to the more powerful astringents, but one not to be wholly relied upon, to the exclusion of other well established therapeutic agents. My firm conviction, however, is, that we frequently meet with cases where the employment of nitric acid would be preferable to any other remedythat is to say, in cases orioinating in noxious effluvia, or specific poisons in the atmosphere; but in all other cases I would prefer the more active mineral and vegetable astringents.

From Dr. Hynes' remarks, I would infer that he supposes the autumnal forms of diarrhoea and dysentery to be epidemic diseases, hence depending upon atmospheric phenomena, and requiring for their removal remedies possessing antiseptic properties which connteract the influences of those subtle poisons: If such be correct, then his theory in all respects holds good; but if, on the other hand, we deduct the cases that arise from irregularities in diet, and not the least unfrequent cases arising from heat and cold, thise attributable to epidemic sources will, I fear, be found to constitute the minority: when such cases do occur, I believe them to be generally endemic or sporadic. As yet I have not had an opportunity of trying the effects of nitric acid in dysentery; but if, as Dr. Hynes asserts, it acts chemically upon the mucous membranes, I wonld suggest its exhibition in the form of enema, as being more liable to come into direct contact with the morbid surface.

I am, Sir, your obedient servant,

Wresham, Sept. 1861. KeIth MacdonaLd, L.R.C.S. Edin. 